\title{
A New Optimization Model for 3D Well Design
}

\author{
E.M.E.M. Shokir ${ }^{1}$, M.K. Emera ${ }^{2}$, S.M. Eid ${ }^{3}$ and A.W. Wally ${ }^{2}$ \\ 1 Petroleum Engineering Dept., King Saudi University, PO Box 800, Riyadh 11421 - Saudi Arabia \\ 2 Mining, Petroleum and Metallurgical Engineering Dept., Cairo University - Egypt \\ 3 Electrical Communication Dept., Faculty of Engineering, Cairo University - Egypt \\ e-mail: shokir@ksu.edu.sa \\ ${ }^{*}$ Corresponding author
}

Résumé - Nouveau modèle pour l'optimisation de la conception 3D des puits - Ce travail utilise un logiciel se servant d'un algorithme génétique pour déterminer la profondeur optimale de puits directionnels et horizontaux dans un espace 3D. Nous utilisons une fonction spécifique de pénalité, la mutation, les probabilités croisées et un critère de terminaison pour obtenir le minimum global de profondeur de forage. Ce minimum est atteint aux valeurs minimales du point de démarrage, de l'angle de forage et des taux d'augmentation et de déclin de production. Les valeurs minimales de ces paramètres amoindrissent la sévérité des virages, entraînant une réduction des problèmes en opération. La conception optimisée est comparée pour deux puits à la conception conventionnelle (à base d'une méthode d'essai et d'erreur) et au logiciel WELLDES (à base d'une technique de minimisation séquentielle sans contraintes). La conception optimisée permet de réduire la longueur totale de forage des deux puits, tout en maintenant les autres paramètres opérationnels dans les contraintes imposées. Dans la conception conventionnelle et le logiciel WELLDES, quelques variables sortent de leurs limites de contrainte.

\footnotetext{
Abstract - A New Optimization Model for 3D Well Design - This paper introduces a software package that uses a genetic algorithm to find the optimum drilling depth of directional and horizontal wells in 3D. A special penalty function, mutation, crossover probabilities, and stopping criterion were used to obtain the global minimum of drilling depth. This minimum was achieved at the minimum values for kickoff point, inclination angle, build-up and drop-off rates. The minimum values of these parameters reduce the dogleg severity, which in turn reduce the drilling operation problems. The optimized design was compared to the conventional design (based on a trial and error method) and the WELLDES program (based on sequential unconstrained minimization technique) for two wells. The optimized design reduced the total drilling length of the two wells, while all other operational parameters were kept within the limiting constraints. The conventional design and WELLDES program have some variables out of their constraint limits
} 


\section{NOMENCLATURE}

a curvature of the curve, radians $/ \mathrm{m}$

Fit $_{i} \quad$ fitness value of chromosome $i$, fraction

$H D \quad$ horizontal section, $\mathrm{m}$

$D_{K O P} \quad$ depth of kickoff point, $\mathrm{m}$

$T D_{M} \quad$ total drilling measured depth, $\mathrm{m}$

$T \quad$ dogleg severity, ${ }^{\circ} / 30.48 \mathrm{~m}$

$A N G 1 U$ upper limit on inclination angle after first build section, $\mathrm{m}$

$A N G 2 U$ upper limit on inclination angle after drop section, $\mathrm{m}$

$A N G 3 U$ upper limit on inclination angle after second build section, $\mathrm{m}$

ANG1L lower limit on inclination angle after first build, $\mathrm{m}$

$A N G 2 L$ lower limit on inclination angle after drop section, $\mathrm{m}$

ANG3L lower limit on inclination angle after second build section, $\mathrm{m}$

$D K M A X \quad$ upper limit on depth of kickoff point, $\mathrm{m}$

$D K M I N$ lower limit on depth of kickoff point, $\mathrm{m}$

$C A S D 1 U$ upper limit on casing setting depth after first build, $m$

$C A S D 2 U$ upper limit on casing setting depth after drop section, $\mathrm{m}$

$C A S D 3 U$ upper limit on casing setting depth after second build section, $\mathrm{m}$

CASD1L lower limit on casing setting depth after first build, $m$

$C A S D 2 L$ lower limit on casing setting depth after drop section, $\mathrm{m}$

$C A S D 3 L$ lower limit on casing setting depth after second build section, $\mathrm{m}$

$D_{v 2} \quad$ true vertical depth after at end of first hold section, $\mathrm{m}$

$D_{v 3} \quad$ true vertical depth after at end of drop section, $\mathrm{m}$

$A A N G 1 U$ upper limit on azimuth angle at kickoff point, degrees

$A A N G 2 U$ upper limit on azimuth angle after first build, degrees

$A A N G 3 U$ upper limit on azimuth angle after first hold section, degrees

$A A N G 4 U$ upper limit on azimuth angle after drop section, degrees

$A A N G 5 U$ upper limit on azimuth angle after second hold section, degrees

$A A N G 6 U$ upper limit on azimuth angle after second build section, degrees

$A A N G 1 L$ lower limit on azimuth angle at kickoff point, degrees
$A A N G 2 L$ lower limit on azimuth angle after first build, degrees

$A A N G 3 L$ lower limit on azimuth angle after first hold section, degrees

$A A N G 4 L$ lower limit on azimuth angle after drop section, degrees

AANG5L lower limit on azimuth angle after second hold section, degrees

$A A N G 6 L$ lower limit on azimuth angle after second build section, degrees

$d l s 1 \quad$ upper limit on dogleg severity of first build section, ${ }^{\circ} / 30.48 \mathrm{~m}$

$d l s 2 \quad$ upper limit on dogleg severity of first hold section, ${ }^{\circ} / 30.48 \mathrm{~m}$

dls3 upper limit on dogleg severity of drop section, \%/30.48 m

$d l s 4 \quad$ upper limit on dogleg severity of second hold section, ${ }^{\circ} / 30.48 \mathrm{~m}$

$d l s 5 \quad$ upper limit on dogleg severity of second build section, ${ }^{\circ} / 30.48 \mathrm{~m}$

$r \quad$ radius of curvature, $\mathrm{m}$

$R_{i} \quad$ radius of curvature of $i$ section, m

$T_{i} \quad$ dogleg severity of $i$ section, ${ }^{\circ} / 30.48 \mathrm{~m}$

TVD true vertical depth, $\mathrm{m}$

$\Delta E W_{i} \quad$ incremental of east-west, $\mathrm{m}$

$\triangle N S_{i} \quad$ incremental of north-south, $\mathrm{m}$

$\Delta T V D_{i} \quad$ incremental of true vertical depth, $\mathrm{m}$

$n \quad$ population size

NPVs net present values

$P c \quad$ crossover probability, $\%$

Pen penalty function value

Peni penalty of variable $i$

Pm mutation probability, \%

$R f i \quad$ ratio factor of survey point $i$

$\lambda$ parameter in mutation equation.

\section{INTRODUCTION}

Minimizing the cost of drilling a directional or horizontal well is a major concern for drilling engineers. Cost is traditionally optimized by improving elements of the operations such as bit selection, weight on bit and rotary speed, drilling time, casing length. Optimizing well trajectory in case of 3D deviated wells directly impacts on well costs which include casing length, cemented parts, mud volumes, drilling time, etc. A review of the literature published in the last two decades shows that well design depends strongly on the designer's experience and judgment; and, the results obtained are not necessarily the best because of lack of strict mathematical models and corresponding optimization theories. 
Furthermore, the repeated selecting and adjusting of the design parameters is time consuming and inefficient (Miska, 1981; Amara et al., 1990; Rampersad et al., 1993). Helmy et al. (1997) proposed the first practical well-design model based on nonlinear optimization theory, in which the constraints such as kickoff point, build up rate, drop-off rate, inclination, casing setting depth were included. This model was in 2D and was solved using a sequential unconstrained minimization technique. This work was followed by another work to optimizing the well trajectory in 3D, but did not consider the constraint of casing setting depth (Ahmed et al., 1999).

Traditional optimization methods failed to solve many problems for the following reasons (Lewin et al., 2003):

- higher order techniques such as the gradient and Newton's methods need the objective function to be differentiable;

- direct search methods like the random search fail to converge to the optimum in large search spaces;

- some methods are restricted to specific objective functions;

- most of methods fail to reach the global optimum unless the objective function is convex;

- all methods deal only with continuous variables.

The objectives of this work are to develop a software package using a genetic algorithm to optimize the directional and horizontal well design parameters in order to minimize the total measured depth by increasing the probability of finding the global optimum, instead of moving point to point in the search space (traditional methods), and hence, to reduce the drilling cost. This program includes the constraints; such as kickoff point, build up rate, drop-off rate, inclination, casing setting depth and maintains all other parameters constant (e.g. mud properties, hydraulics, bits types). The genetic optimization design is compared to the conventional design, "application A", and the WELLDES program (Ahmed et al., 1999), "application B".

\section{GENTIC ALGORITHMS}

Genetic algorithms (GAs) were invented to mimic some of the processes observed in natural evolution (Davis, 1991). GAs are a family of computational methods inspired by evolution. These algorithms encode a potential solution to a specific problem on a simple chromosome-like data structure and apply recombination operators to this structure so as to preserve critical information. Genetic algorithms are often viewed as function optimizers, although the range of problems to which genetic algorithms have been applied is quite broad (Tate et al., 1995).

An implementation of a genetic algorithm begins with a population of typically random chromosomes. One then creates a set of solutions, testing them against a given problem, and then "breeding" a new set of solutions based on some measure of success. In the case of a genetic algorithm, we "evolve" a solution to some specific problem, such as minimizing a traveling salesman's route, by emulating nature. Fortunately, the software universe is far less complex than the biological world and no piece of software can, or needsto, incorporate all of life's techniques. Whereas living things need to seek flexible roles in variable environments, computer algorithms often need only to find a specific answer to a fixed question (Reeves, 1997).

This particular description of a genetic algorithm is intentionally abstract because in some sense, the term genetic algorithm has two meanings. In a strict interpretation, the genetic algorithm refers to a model introduced and investigated by Holland (1975) and by Goldberg (1989). It is still the case that most of the existing theory of genetic algorithms applies either solely or primarily to the model introduced by Holland.

In a broader usage of the term, a genetic algorithm is any population-based model that uses selection and recombination operators to generate new sample points in a search space. Researchers largely working from an experimental perspective have introduced many genetic algorithm models. Many of these researchers applications are oriented and typically interested in genetic algorithms as optimization tools.

The steps in executing the genetic algorithm are as following:

1 Randomly, create an initial population of individual chromosomes;

2 Iteratively perform the following substeps on the population of chromosomes until the termination criterion has been satisfied:

- assign a fitness value to each individual in the population using the fitness measure;

- create a new population of chromosomes by applying the following operation:

- Selection: select two chromosomes, according to their fitness. The two selected chromosomes are called parents.

. Crossover: take a copy of the selected parents and apply a crossover operation on them, with a certain probability, to produce two new children.

- Mutation: the two children, produced after the crossover operation, are then mutated, with a certain probability, to produce two new children.

- Deletion: the resulting children after mutation are compared with their parents, the best two of the four chromosomes replaces the two parents.

3 The best chromosome in the population (i.e., with the highest fitness) represents a solution (or an approximated solution) to the problem.

The authors refer the reader to a recent feature articles from Sevaux et al. (2003), Pongcharoen et al. (2003), Vijande et al. (2003), and Reeves (1997) for an extensive description of genetic algorithm operations. 


\section{STATEMENT OF THE PROBLEM}

A general horizontal well trajectory is considered for the well design problem. A schematic vertical plan of the 3D general horizontal well trajectory is shown in Figure 1. Solutions of special cases, (e.g. build and hold and build, hold, and build trajectory) are derived from the general solution of the problem.

The problem is stated as: given the coordinates of the surface and the down hole target locations and constraints of the well; determine the optimum directional well design parameters which satisfy the minimum drilling depth.

\section{MODEL FORMULATION}

Three steps are required for the formulation of this optimization problem as following:

1 Identify the system,

- collect data to describe the system: collect all related data to the well under consideration (e.g. geologic data, surface and target coordinate, etc);
- identify system variables;

- system constraints: constraints are all restrictions placed on the system. These constraints could take the form of either equalities or inequalities.

2 Find a measure of system effectiveness: a criterion must be defined in order to judge the effectiveness of the system. That criterion is a scalar function called the objective function and is expressed in terms of the system variables and is represented by $f(x)$. The objective function, which gives a maximum or a minimum value, provides the means to compare different solutions in order to select the best one.

3 Apply the optimization technique.

\subsection{System Variables}

A horizontal well trajectory as shown in Figure 1 is considered to generalize the well design problem. The system of horizontal well design is described by all the variables shown in Table 1.

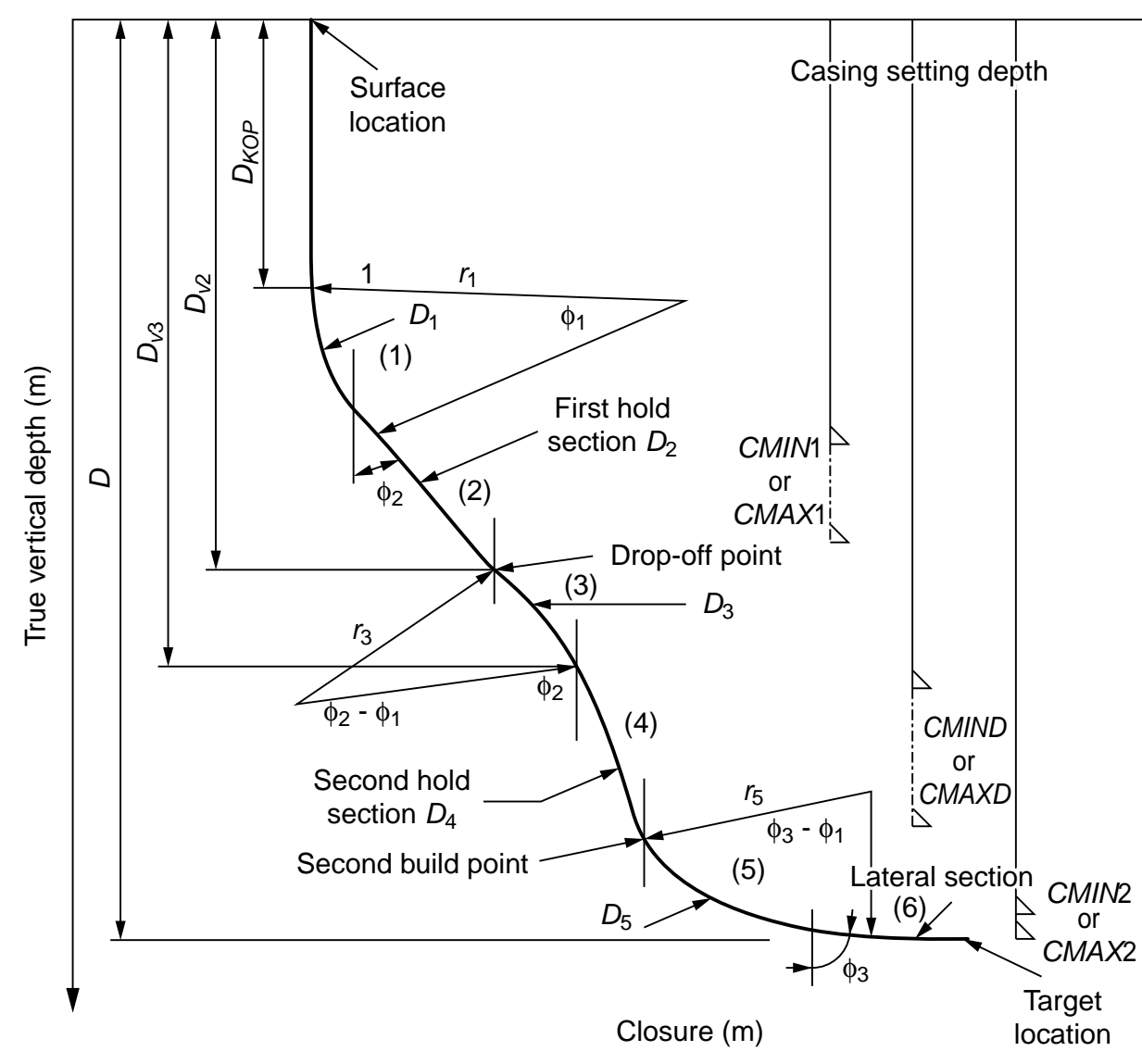

Figure 1

Vertical plan of s general 3D horizontal well trajectory. 
TABLE 1

Outlines the optimum system variables

\begin{tabular}{l|l}
\hline Variable & \multicolumn{1}{c}{ Description } \\
\hline$\phi_{1}, \phi_{2}, \phi_{3}$ & first, second, and third hold angles, degrees \\
\hline$\theta_{1}$ & azimuth angle at kickoff point, degrees \\
\hline$\theta_{2}$ & azimuth angle at end of first build section, degrees \\
\hline$\theta_{3}$ & azimuth angle at end of first hold section, degrees \\
\hline$\theta_{4}$ & azimuth angle at end of drop section, degrees \\
\hline$\theta_{5}$ & azimuth angle at end of second hold section, degrees \\
\hline$\theta_{6}$ & azimuth angle at end of second build section, degrees \\
\hline$T_{1}$ & dogleg severity of first build section, ${ }^{\circ} / 30.48 \mathrm{~m}$ \\
\hline$T_{2}$ & dogleg severity of first hold section, ${ }^{\circ} / 30.48 \mathrm{~m}$ \\
\hline$T_{3}$ & dogleg severity of drop section, ${ }^{\circ} / 30.48 \mathrm{~m}$ \\
\hline$T_{4}$ & dogleg severity of second hold section, ${ }^{\circ} / 30.48 \mathrm{~m}$ \\
\hline$T_{5}$ & dogleg severity of second build section, ${ }^{\circ} / 30.48 \mathrm{~m}$ \\
\hline$T V D$ & true vertical depth of the well, $\mathrm{m}$ \\
\hline$D_{K O P}$ & true vertical depth of kickoff point, $\mathrm{m}$ \\
\hline$D_{v 2}$ & true vertical depth at the end of first hold section, $\mathrm{m}$ \\
\hline$D_{v 3}$ & true vertical depth at the end of drop section, $\mathrm{m}$ \\
\hline
\end{tabular}

\subsection{System Objective Function}

The objective function of the system is the measured drilling depth that used to judge the effectiveness of the well design. This function is a mathematical expression that represents the measured drilling depth of the horizontal well as a function of the system variables in three dimensions.

In contrast to many references (Wilson, 1968; Callas, 1976; Taylor, 1972) many methods used in planning the directional and horizontal wells, McMillian, 1981, described the radius of curvature calculation of the $3 \mathrm{D}$ path of the directionally drilled well from kickoff point as a function of inclination as well as direction. The constant curvature equation between two points in space as shown in Figure 2 is:

$$
a=\frac{1}{\Delta M} \sqrt{\left(\theta_{2}-\theta_{1}\right)^{2} \sin ^{4}\left(\left(\phi_{1}-\phi_{2}\right) / 2\right)+\left(\phi_{2}-\phi_{1}\right)^{2}}
$$

and the radius of curvature is:

$$
r=\frac{1}{a}=\frac{5486.4}{\pi \times T}
$$

From Equations (1) and (2) the well path between two point in 3D can be calculated as a function of radii of curvature as well as the change of inclination and direction.

$$
\Delta M=r \times \sqrt{\left(\theta_{2}-\theta_{1}\right)^{2} \sin ^{4}\left(\left(\phi_{1}-\phi_{2}\right) / 2\right)+\left(\phi_{2}-\phi_{1}\right)}
$$

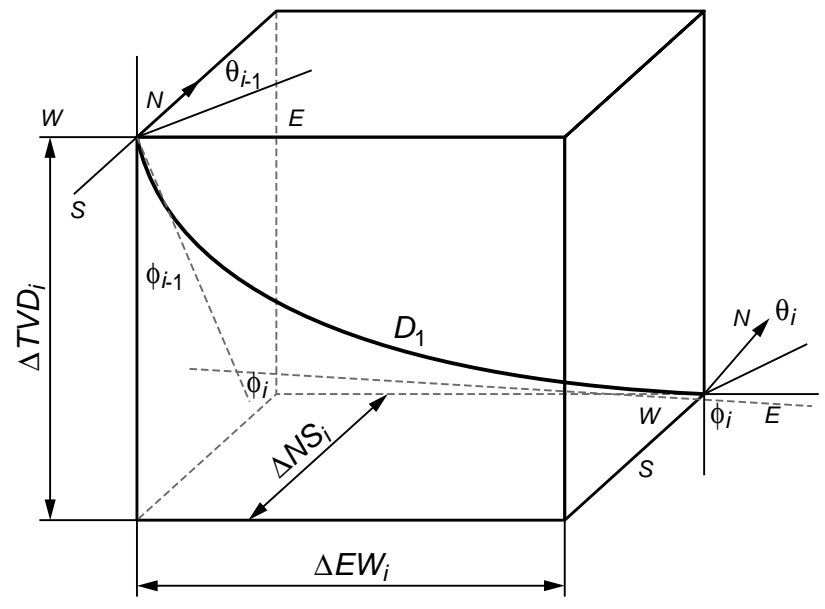

Figure 2

Surveys calculation variables (Adams, 1985).

So, from Figure 1 a general equation to calculate the well path of a horizontal well consists of seven segments, kickoff segment, $D_{k o p}$, three segment for build and drop $D_{1}, D_{2}, D_{3}$, two hold segment $D_{4}, D_{5}$, and final lateral section in the target layer $H D$, as following:

$$
\begin{gathered}
T D_{M}=D_{K O P}+D_{1}+D_{2}+D_{3}+D_{4}+D_{5}+H D \\
D_{1}=r_{1} \times\left(\left(\theta_{2}-\theta_{1}\right)^{2} \sin ^{4}\left(\phi_{1} / 2\right)+\left(\phi_{1}\right)^{2}\right)^{0.5} \\
D_{2}=\left(D_{v 2}-D_{K O P}-D_{1} \times\left(\sin \left(\phi_{1}\right)-\sin \left(\phi_{K O P}\right)\right) /\left(\phi_{1} \phi_{K O P}\right)\right) \\
\quad / \cos \left(\phi_{1}\right) \\
D_{3}=r_{3} \times\left(\left(\theta_{4}-\theta_{3}\right)^{2} \sin ^{4}\left(\left(\phi_{2}+\phi_{1}\right) / 2\right)+\left(\phi_{2}-\phi_{1}\right)^{2}\right)^{0.5} \\
D_{4}=\left(D_{v 3}-D_{v 2}-D_{3} \times\left(\sin \left(\phi_{2}\right)-\sin \left(\phi_{1}\right)\right) /\left(\phi_{2}-\phi_{1}\right)\right) \\
\quad / \cos \left(\phi_{2}\right) \\
D_{5}=r_{5} \times\left(\left(\theta_{6}-\theta_{5}\right)^{2} \sin ^{4}\left(\left(\phi_{3}+\phi_{2}\right) / 2\right)+\left(\phi_{3}-\phi_{2}\right)^{2}\right)^{0.5}
\end{gathered}
$$

Where, $\phi_{K O P}=$ inclination angle at kickoff point, which was assumed to equal zero (Adam, 1985), and $r_{1}, r_{2}$ and $r_{3}$ can be calculated as:

$$
\begin{gathered}
r_{i}=\frac{5486.4}{\pi \times T_{i}},-i=1,2, \ldots, 5 \\
C_{1}=D_{K O P}+D_{1} \times \sin \left(\phi_{1}\right) / \phi_{1}
\end{gathered}
$$




$$
\begin{gathered}
C_{2}=D_{K O P}+\left(D_{1} \times \sin \left(\phi_{1}\right) / \phi_{1}\right)+D_{2} \times \cos \left(\phi_{1}\right) \\
+\left(D_{3} \times\left(\sin \left(\phi_{2}\right)-\sin \left(\phi_{1}\right)\right) /\left(\phi_{2}-\phi_{1}\right)\right) \\
C_{3}=D_{K O P}+\left(D_{1} \times \sin \left(\phi_{1}\right) / \phi_{1}\right)+D_{2} \times \cos \left(\phi_{1}\right) \\
+\left(D_{3} \times\left(\sin \left(\phi_{2}\right)-\sin \left(\phi_{1}\right)\right) /\left(\phi_{2}-\phi_{1}\right)\right) \\
+D_{4} \times \cos \left(\phi_{2}\right) \\
+\left(D_{5} \times\left(\sin \left(\phi_{3}\right)-\sin \left(\phi_{2}\right)\right) /\left(\phi_{3}-\phi_{2}\right)\right. \\
D L_{A 1}=T_{1} \times D_{1} / 30.48 \\
D L_{A 2}=T_{2} \times D_{2} / 30.48 \\
D L_{A 3}=T_{3} \times D_{3} / 30.48 \\
D L_{A 4}=T_{4} \times D_{4} / 30.48 \\
D L_{A 5}=T_{5} \times D_{5} / 30.48
\end{gathered}
$$

Where,

$D L_{A 1}=$ dogleg angle of first build section $\left(D L_{A 1}=\phi_{1}\right)$, degrees (Rabia, 1985)

$D L_{A 2}=$ dogleg angle of first hold section $\left(D L_{A 2} \cong 0\right)$, degrees

$D L_{A 3}=$ dogleg angle of drop section or second build section $\left(D L_{A 3}=\phi_{2}-\phi_{1}\right)$, degrees

$D L_{A 4}=$ dogleg angle of second hold section $\left(D L_{A 4} \cong 0\right)$, degrees, and

$D L_{A 5}=$ dogleg angle of third build section $\left(D L_{A 5}=\phi_{3}-\phi_{2}\right)$, degrees.

Well surveys were calculated based on the minimum curvature method (Adam, 1985). which is the most accurate method. This method gives the changes or increments in north-south $\left(\Delta N S_{i}\right)$, east-west $\left(\Delta E W_{i}\right)$, and the true vertical depth $\left(\Delta T V D_{i}\right)$ at any point.

\subsection{System Constraints}

To locate the minimum depth; constraints are set to control the selection of the optimum set of the designed variables. Two different types of constraints are defined for the designed problem.

\subsubsection{Operational Constraints}

The operational constraints are those constraints that are imposed on the well design due to different types of formation to be drilled, casing setting depths, limitations of variable equipment or technology, and other operations.

$$
\begin{aligned}
& \phi_{1} \leq A N G 1 U \text { and } \phi_{1} \geq A N G 1 L \\
& \phi_{2} \leq A N G 2 U \text { and } \phi_{2} \geq A N G 2 L \\
& \phi_{3} \leq A N G 3 U \text { and } \phi_{3} \geq A N G 3 L
\end{aligned}
$$

$$
\begin{gathered}
T_{1} \leq d l s 1 \\
T_{2} \leq d l s 2 \\
T_{3} \leq d l s 3 \\
T_{4} \leq d l s 4 \\
T_{5} \leq d l s 5 \\
\theta_{1} \leq A A N G 1 U \text { and } \theta_{1} \geq A A N G 1 L \\
\theta_{2} \leq A A N G 2 U \text { and } \theta_{2} \geq A A N G 2 L \\
\theta_{3} \leq A A N G 3 U \text { and } \theta_{3} \geq A A N G 3 L \\
\theta_{4} \leq A A N G 4 U \text { and } \theta_{4} \geq A A N G 4 L \\
\theta_{5} \leq A A N G 5 U \text { and } \theta_{5} \geq A A N G 5 L \\
\theta_{6} \leq A A N G 6 U \text { and } \theta_{6} \geq A A N G 6 L \\
D_{K O P} \leq D K M A X \text { and } D_{K O P} \geq D K M I N \\
D_{v 2} \leq D V 2 M A X \text { and } D_{v 2} \geq D V 2 M I N \\
D_{v 3} \leq D V 3 M A X \text { and } D_{v 3} \geq D V 3 M I N \\
C_{1} \leq C A S D 1 U \text { and } C_{1} \geq C A S D 1 L \\
C_{2} \leq C A S D 2 U \text { and } C_{2} \geq C A S D 2 L \\
C_{3} \leq C A S D 3 U \text { and } C_{3} \geq C A S D 3 L
\end{gathered}
$$

Constraints (19) to (21): these constraints set the upper and lower limits for the hold angles $\left(\phi_{1}, \phi_{2}\right.$ and $\left.\phi_{3}\right)$. High build-up or drop-off angles result in high torque and drag, and require high strength drill pipe; a condition which increase the well cost.

Constraints (22) to (26): these constraints set the upper limit for the dogleg severity $\left(T_{1}, T_{2}, T_{3}, T_{4}\right.$, and $\left.T_{5}\right)$, whereas high dogleg severity in the well results in high torque and drag.

Constraints (27) to (32): these constraints set the upper and lower limits for the azimuth angle. These constraints are set to allow the designer to turn in $3 \mathrm{D}$ around any obstacles to reach the target, for example to solve a geologic problem like dip of the formation.

Constraints (33) to (35): these constraints set the upper and lower limits for the kickoff and drop-off depths. It is usually preferable to kick the well off in hard formation with an angle building assembly. However, it is preferable to drop the well off in a soft formation with a pendulum assembly.

Constraints (36) to (38): these constraints set the upper and lower limits for the casing setting depths after building and dropping the angle. The casing setting point is supposed to be in competent formation to provide pressure integrity for the casing shoe after cementing. After building the angle, it might be required to case the hole prior to drilling the following sections of the well in order to avoid key seating. 


\subsubsection{Nonnegativity Constraints}

The nonnegativity constraints are those constraints imposed on the well design model to ensure that certain components of the model are always positive. The following are the nonnegativity constraints used in this study:

$$
D_{1} \geq 0 \text { and } D_{2} \geq 0
$$

\section{PROBLEM SOLUTION - GENETIC ALGORITHM SOFTWARE}

Genetic algorithm software using FORTRAN language is developed to solve the directional well optimization problem. Figure 3 shows the program flow chart.

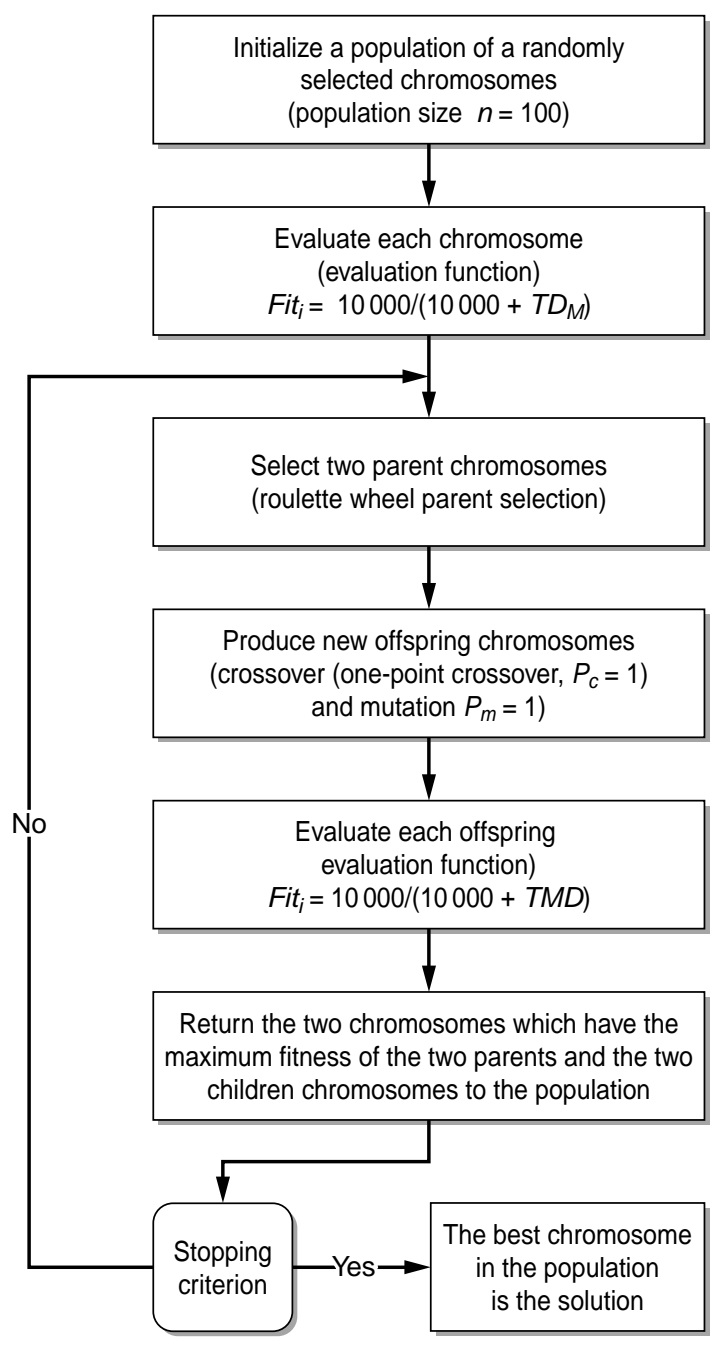

Figure 3

Flow chart for optimized well design using genetic algorithm.

\subsection{Initial Population}

In the genetic algorithm software, chromosome value encoding is selected using real numbers to encode the problem variables on GA chromosomes. Then, each variable (gene) has a random value to build an initial random population. The population size is selected to equal 100 chromosomes in the population; each chromosome presents a solution to the problem.

\subsection{Evaluation Function}

After building the initial population, each chromosome (solution) in the population is evaluated according to a fitness value that is a function of the objective function (true measured depth). This fitness value can be calculated as follows:

$$
F i t_{i}=10000 /\left(10000+T D_{M}\right)
$$

Where, Fit $_{i}=$ fitness function value, fraction. And the constant value $(\mathrm{C}=10000)$ is a selectable value to prevent to the value of Fit $_{i}$ being too small.

Each variable (gene) has a constraint limit. If any variable has a value that out of this limit, the fitness value must be reduced by a certain value called a penalty function value. This penalty function is used to penalize the chromosome (solution) to re-enter its variables into their constraint limits. If any variable has a value that is less than its minimum value or greater than its maximum value (constraint limit), then:

$$
F i t_{i}(\text { new })=F i t_{i}(\text { old }) \times(1-\text { pen })
$$

Where, pen $=$ penalty function value.

\subsection{Selection}

The selection method that used in the software is roulette wheel parent selection to select two parents (chromosomes) from the population to produce two children from them by reproduction operators. This method is selected because it is faster than other methods (e.g., tournament parent selection, Tate, 1995).

\subsection{Reproduction Operators}

\subsubsection{Crossover}

The crossover type used in this software is one-point crossover. In this type, one point is selected randomly, the two parent chromosomes are cut at this point then alternate pairs of sections are exchanged between the first part of one parent and the last part of the other parent. After this crossover, two children chromosomes (new solutions) are produced. The selected probability of crossover $(P c)$ is equal to $100 \%$. 


\subsubsection{Mutation}

After crossover and producing two children chromosomes, then one gene is selected from each child chromosome to mutate its value. This mutation technique operates by changing the value of the variable (gene) by adding a random value to its old value as follows:

New value $=$ old value $+(1-\lambda) \times$ random value,

$$
0 \leq \lambda \leq 1
$$

Where, $\lambda=0.99$ is selected in the software.
The selected probability value of mutation $(\mathrm{Pm})$ is equal to $100 \%$. Then after producing the two children chromosomes, they must be evaluated to get their fitness values.

\subsubsection{Deletion}

After producing the offspring, two chromosomes of the two parents and the two children chromosomes must be inserted into the population. This occurs in the software by determining the best two chromosomes (the two chromosomes that have the maximum two fitness) from the two parents and the two children chromosomes, and inserting them into the

TABLE 2

Input data for the two applications

\begin{tabular}{|c|c|c|}
\hline The variables & $\begin{array}{l}\text { Application A } \\
\text { (actual well from Gulf of Suez, Egypt) }\end{array}$ & $\begin{array}{l}\text { Application B } \\
\text { (theoretical well) }\end{array}$ \\
\hline $\begin{array}{l}\text { Surface coordinates } \\
\text { from a reference point }\end{array}$ & $\begin{array}{l}\text { North-south: } 1.28 \mathrm{~m} \\
\text { East-west: }-7.9 \mathrm{~m}\end{array}$ & $\begin{array}{l}\text { North-south: } 0.0 \mathrm{~m} \\
\text { East-west: } 0.0 \mathrm{~m}\end{array}$ \\
\hline $\begin{array}{l}\text { Target coordinates } \\
\text { from a reference point, start point }\end{array}$ & $\begin{array}{l}\text { North-south: } 1197.6 \mathrm{~m} \\
\text { East-West: }-954 \mathrm{~m}\end{array}$ & $\begin{array}{l}\text { North-south: } 569 \mathrm{~m} \\
\text { East-west: } 705.6 \mathrm{~m}\end{array}$ \\
\hline $\begin{array}{l}\text { Target coordinates } \\
\text { from a reference point, end point }\end{array}$ & $\begin{array}{l}\text { North-south: } 195.7 \mathrm{~m} \\
\text { East-sest: }-983.9 \mathrm{~m}\end{array}$ & $\begin{array}{l}\text { North-south: } 605 \mathrm{~m} \\
\text { East-west: } 1222.5 \mathrm{~m}\end{array}$ \\
\hline Target true vertical & $\begin{array}{l}\text { Min. } T V D=3307 \mathrm{~m} \\
\text { Max. } T V D=3322 \mathrm{~m}\end{array}$ & $\begin{array}{l}\text { Min. } T V D=2860.5 \mathrm{~m} \\
\text { Max. } T V D=2875.8 \mathrm{~m}\end{array}$ \\
\hline Lateral section length, $H D$ & $762 \mathrm{~m}$ & $518 \mathrm{~m}$ \\
\hline Dogleg severity & $\begin{array}{l}T_{1} \leq 5^{\circ} / 30.48 \mathrm{~m}, T_{2} \leq 5 \% 30.48 \mathrm{~m} \\
T_{3} \leq 5^{\circ} / 30.48 \mathrm{~m}, T_{4} \leq 5 \% 30.48 \mathrm{~m} \\
T_{5} \leq 5^{\circ} / 30.48 \mathrm{~m}\end{array}$ & $\begin{array}{l}T_{1} \leq 5^{\circ} / 30.48 \mathrm{~m}, T_{2} \leq 1 \% / 30.48 \mathrm{~m} \\
T_{3} \leq 5^{\circ} / 30.48 \mathrm{~m}, T_{4} \leq 1 \% 30.48 \mathrm{~m} \\
T_{5} \leq 10^{\circ} / 30.48 \mathrm{~m}\end{array}$ \\
\hline Minimum value of inclination angles & $\phi_{1}=10^{\circ}, \phi_{2}=40^{\circ}, \phi_{3}=90^{\circ}$ & $\phi_{1}=10^{\circ}, \phi_{2}=30^{\circ}, \phi_{3}=90^{\circ}$ \\
\hline Maximum value of inclination angles & $\phi_{1}=20^{\circ}, \phi_{2}=70^{\circ}, \phi_{3}=95^{\circ}$ & $\phi_{1}=30^{\circ}, \phi_{2}=50, \phi_{3}=95^{\circ}$ \\
\hline Minimum value of azimuth angles & $\begin{array}{l}\theta_{1}=270^{\circ}, \theta_{2}=270^{\circ}, \theta_{3}=270^{\circ} \\
\theta_{4}=330^{\circ}, \theta_{5}=330^{\circ}, \theta_{6}=355^{\circ}\end{array}$ & $\begin{array}{l}\theta_{1}=300^{\circ}, \theta_{2}=300^{\circ}, \theta_{3}=300^{\circ} \\
\theta_{4}=360^{\circ}, \theta_{5}=360^{\circ}, \theta_{6}=360^{\circ}\end{array}$ \\
\hline Maximum value of azimuth angles & $\begin{array}{l}\theta_{1}=280^{\circ}, \theta_{2}=280^{\circ}, \theta_{3}=280^{\circ} \\
\theta_{4}=340^{\circ}, \theta_{5}=340^{\circ}, \theta_{6}=360^{\circ}\end{array}$ & $\begin{array}{l}\theta_{1}=360^{\circ}, \theta_{2}=360^{\circ}, \theta_{3}=360^{\circ} \\
\theta_{4}=460^{\circ}, \theta_{5}=460^{\circ}, \theta_{6}=460^{\circ}\end{array}$ \\
\hline Kickoff point depth & $\begin{array}{l}\text { Min. } D_{K O P}=182.8^{*} \mathrm{~m} \\
\text { Max. } D_{K O P}=304.8^{*} \mathrm{~m}\end{array}$ & $\begin{array}{l}\text { Min. } D_{K O P}=152.4^{*} \mathrm{~m} \\
\text { Max. } D_{K O P}=609.6^{*} \mathrm{~m}\end{array}$ \\
\hline Vertical depth after first hold section & $\begin{array}{l}\text { Min. } D_{v 2}=1828.8^{*} \mathrm{~m} \\
\text { Max. } D_{v 2}=2133.6^{*} \mathrm{~m}\end{array}$ & $\begin{array}{l}\text { Min } D_{v 2}=609.6^{*} \mathrm{~m} \\
\text { Max. } D_{v 2}=2133.6^{*} \mathrm{~m}\end{array}$ \\
\hline Vertical depth after drop section & $\begin{array}{l}\text { Min. } D_{v 3}=3048^{*} \mathrm{~m} . \\
\text { Max. } D_{v 3}=3108.9^{*} \mathrm{~m}\end{array}$ & $\begin{array}{l}\text { Min. } D_{v 3}=2438.4^{*} \mathrm{~m} \\
\text { Max. } D_{v 3}=3048^{*} \mathrm{~m}\end{array}$ \\
\hline Casing setting depth after first build & $\begin{array}{l}\text { Min. } C_{1}=548.6^{*} \mathrm{~m} . \\
\text { Max. } C_{1}=670.6^{*} \mathrm{~m}\end{array}$ & $\begin{array}{l}\text { Min. } C_{1}=457.2^{*} \mathrm{~m} \\
\text { Max. } C_{1}=1219.2^{*} \mathrm{~m}\end{array}$ \\
\hline Casing setting depth after drop section & $\begin{array}{l}\text { Min. } C_{2}=2194.6^{*} \mathrm{~m} . \\
\text { Max. } C_{2}=2651.7^{*} \mathrm{~m}\end{array}$ & $\begin{array}{l}\text { Min. } C_{2}=2133.6^{*} \mathrm{~m} \\
\text { Max. } C_{2}=2743.2 * \mathrm{~m}\end{array}$ \\
\hline Casing setting depth after 2 nd build & $\begin{array}{l}\text { Min. } C_{3}=3139.4^{*} \mathrm{~m} . \\
\text { Max. } C_{3}=3352.8^{*} \mathrm{~m}\end{array}$ & $\begin{array}{l}\text { Min. } C_{3}=2743.2 * \mathrm{~m} \\
\text { Max. } C_{3}=3048 * \mathrm{~m}\end{array}$ \\
\hline
\end{tabular}

* True vertical depth. 
TABLE 3

Output results of GA design in comparison with conventional design, and WELLDES program design for application A

\begin{tabular}{|c|c|c|c|}
\hline The variables & Conventional design & WELLDES design & GA design \\
\hline True measured depth, $\mathrm{m}$ & 4744.2 & 4723.79 & 4723.0 \\
\hline Casing setting depth after $1^{\text {st }}$ build, $\mathrm{m}$ & Neglect & Neglect & 549.2 \\
\hline Casing setting depth after drop section, $\mathrm{m}$ & Neglect & Neglect & 2651.76 \\
\hline Casing setting depth after $2^{\text {nd }}$ build, $m$ & Neglect & Neglect & 3302.569 \\
\hline$T V D, \mathrm{~m}$ & $3306.47^{* *}$ & 3306.56 ** & 3307.08 \\
\hline Target north-south, m & 1915.36 & 1915.36 & 1907.134 \\
\hline Target east-west, $\mathrm{m}$ & $-991.2^{* * *}$ & $-992.4^{* *}$ & -954.1 \\
\hline$D_{K O P}, \mathrm{~m}$ & 190.5 & 191.1 & 301.1 \\
\hline Depth of drop section, $m$ & $2011.68^{*}$ & $1980.8^{*}$ & $2074.0^{*}$ \\
\hline Depth of $2^{\text {nd }}$ build point, $m$ & $3432.04^{*}$ & $3049.06^{*}$ & $3049.35^{*}$ \\
\hline$\phi_{1}$, degrees & 15 & 13.92 & 13.77 \\
\hline$\phi_{2}$, degrees & 45 & 40.02 & 42.131 \\
\hline$\phi_{3}$, degrees & 90 & 90.05 & 90 \\
\hline$\theta_{1}$, degrees & - & $280.1^{* * *}$ & 279.976 \\
\hline$\theta_{2}$, degrees & - & $280.1^{* *}$ & 279.72 \\
\hline$\theta_{3}$, degrees & - & $280.1^{* * *}$ & 275.02 \\
\hline$\theta_{4}$, degrees & - & 332.4 & 332.3 \\
\hline$\theta_{5}$, degrees & - & 332.3 & 334.32 \\
\hline$\theta_{6}$, degrees & - & 353.5 & 355 \\
\hline$T_{1},{ }^{\circ} / 30.48 \mathrm{~m}$ & 0.9 & 0.7 & 1.675 \\
\hline 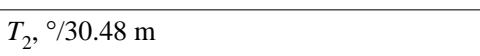 & 0.0 & 00 & 0.047 \\
\hline$T_{3}, \circ / 30.48 \mathrm{~m}$ & 2 & 1.2 & 1.431 \\
\hline 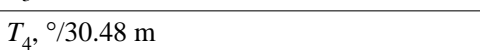 & 0.0 & 0.0 & -0.0102 \\
\hline 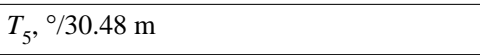 & 3.5 & 2.6 & 2.413 \\
\hline
\end{tabular}

* Measured depth.

** The variables in bold are out of their constraints limits.

population to improve the population (group of solutions). These two chromosomes inserted into the population may be the two children or may be the two parents or may be one parent and one child according to their fitness values.

\subsection{Stopping Criterion}

If the best fitness (the maximum fitness) in the population is equal the average fitness of the whole population, then the software stops and the chromosome, that has the best fitness, is the solution of the problem and its variables (genes) are the optimum values of the problem variables. Otherwise, if the best fitness not equal the average fitness of the population, then the cycle will be continued to select two parents and produce two children until the stopping criterion is achieved.

\section{APPLICATIONS OF GA SOFTWARE IN DIRECTIONAL DRILLING DESIGN}

Table 2 contains the input data for the two applications. The optimum design results of GA software for the first application are shown in Table 3. Also, the comparison between GA design, WELLDES program (Ahmed et al., 1999) (based on sequential unconstrained minimization technique), and conventional method (based on trial and error method) are outlined in Table 3. Its obvious that GA reduced the true measured depth compared to conventional design by about $22 \mathrm{~m}$, and reduced this depth compared to WELLDES design by about $1 \mathrm{~m}$ (nearly the same). But all variables of GA design are in their constraint limits, contrary to conventional design and WELLDES design where some variables are out 
TABLE 4

Output results of GA design in comparison with conventional design for application B

\begin{tabular}{|c|c|c|}
\hline The variables & Conventional design & GA design \\
\hline True measured depth, m & 3962.4 & 3928.649 \\
\hline Casing setting depth after $1^{\text {st }}$ build, $\mathrm{m}$ & Neglect & 498.7473 \\
\hline Casing setting depth after drop section, $\mathrm{m}$ & Neglect & 2466.064 \\
\hline Casing setting depth after $2^{\text {nd }}$ build, $\mathrm{m}$ & Neglect & 2856.198 \\
\hline TVD, $\mathrm{m}$ & 2868.38 & 2860.548 \\
\hline Target north-south, m & 604.9 & 569.2384 \\
\hline Target east-west, m & 1211.7 & 1119.305 \\
\hline$D_{K O P}, \mathrm{~m}$ & 304.8 & 284.7611 \\
\hline Depth of drop section, m & $1524^{*}$ & 2027.301 \\
\hline Depth of $2^{\text {nd }}$ build point, $m$ & $3048^{*}$ & 2466.1 \\
\hline$\phi_{1}$, degrees & 20 & 3.270504 \\
\hline$\phi_{2}$, degrees & 40 & 10.59881 \\
\hline$\phi_{3}$, degrees & 90 & 27.432 \\
\hline$\theta_{1}$, degrees & - & 98.19315 \\
\hline$\theta_{2}$, degrees & - & 98.21265 \\
\hline$\theta_{3}$, degrees & - & 98.19132 \\
\hline$\theta_{4}$, degrees & - & 122.6378 \\
\hline$\theta_{5}$, degrees & - & 139.3058 \\
\hline$\theta_{6}$, degrees & - & 133.2689 \\
\hline$T_{1},{ }^{\circ} / 30.48 \mathrm{~m}$ & 1.0 & 0.463144 \\
\hline$T_{2}, \circ / 30.48 \mathrm{~m}$ & 0.0 & 0.001082 \\
\hline$T_{3}, \circ / 30.48 \mathrm{~m}$ & 1.0 & 0.520598 \\
\hline$T_{4}, \circ / 30.48 \mathrm{~m}$ & 0.0 & 0.003834 \\
\hline$T_{5}, \circ / 30.48 \mathrm{~m}$ & 3.5 & 0.608929 \\
\hline
\end{tabular}

$*=$ measured depth.

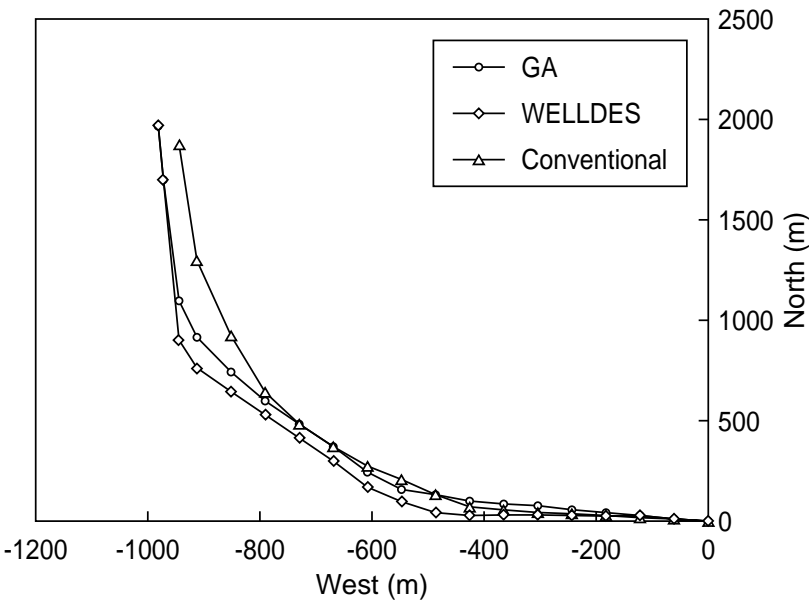

Figure 4

Plan view of application A shows the comparison between optimized GA design, WELLDES program, and conventional design.

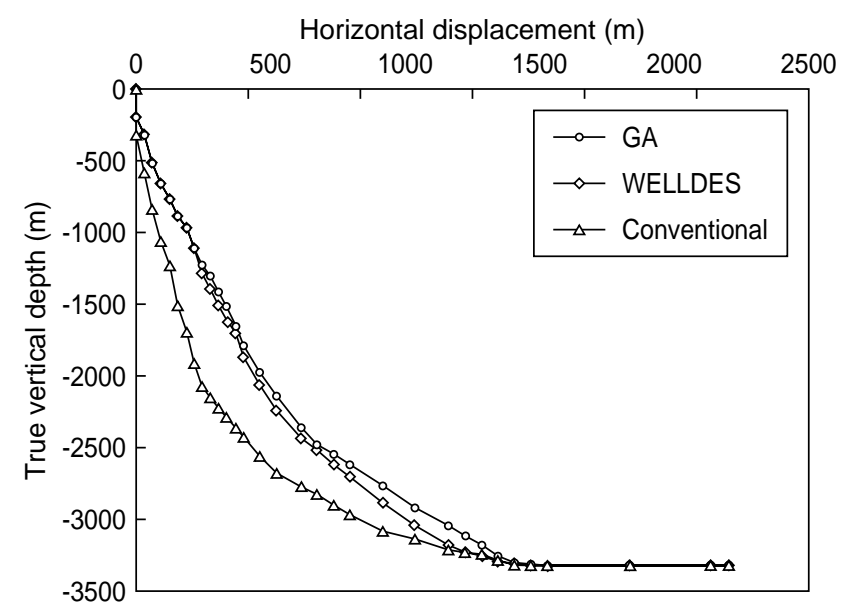

Figure 5

Vertical view of application A shows the comparison between optimized GA design, WELLDES program, and conventional design. 


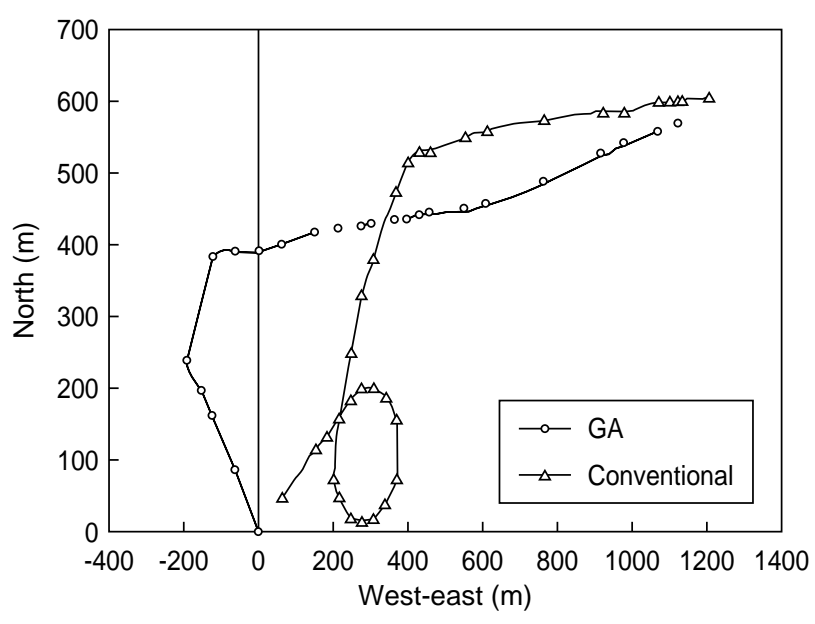

Figure 6

Plan view of application B shows the comparison between optimized GA design and conventional design.

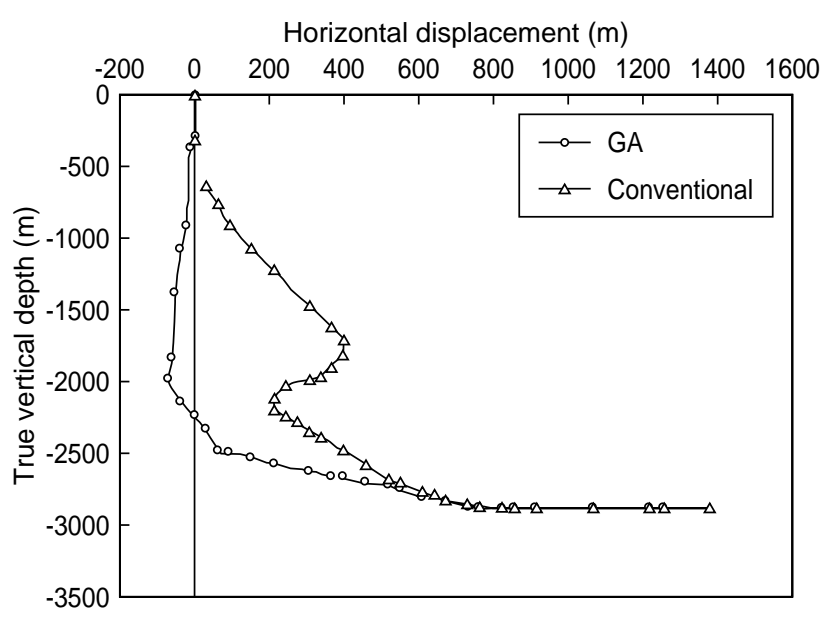

Figure 7

Vertical view of application B shows the comparison between optimized GA design and conventional design. of their constraint limits. In addition, GA take the casing setting depths into consideration, contrary to other designs which do not take them into consideration in their designs. Figures 4 and 5 show the comparisons between GA, conventional, WELLDES designs in horizontal and vertical plan.

Table 4 displays the optimum design results of GA software for the second application and the comparison with the conventional design. It is obvious that GA reduced the true measured depth than conventional design by about $40 \mathrm{~m}$. In addition, GA takes the casing setting depths into consideration, contrary to the conventional design which does not take them into consideration in its design. Figures 6 and 7 show the comparison between GA and conventional design in horizontal and vertical plan.

\section{CONCLUSIONS}

The genetic algorithm proved to be a strong optimization technique.

The comparison between GA software, conventional method, and WELLDES program confirmed the validity of the GA software.

The GA software is easy to use and can be used for any optimization problem by changing the chromosome encoding and evaluation function to suit the required problem.

\section{REFERENCES}

Adams, N.J. (1985) Drilling Engineering: A Complete Well Planning Approach, Penn Well Books, Tulsa, Oklahoma.
Ahmed, K.A., El-Tayeb, S., Dahab, A. and Khalf, F. (1999) 3D well design using computer optimization model. Symposium of SPE Egyptian Section for Computer Application, February, Egypt.

Amara, M.H. and Martin, B. (1990) The off-shore directional drilling adivisor: an expert system for directional drilling optimization. Presented at the 65th Annual Technical Conference and Exhibition of the Society of Petroleum Engineers, SPE 20419. New Orleans, LA, September 23-26.

Callas, N.P. (1976) Computing directional surveys with a helical method, December. SPEJ.

Davis, L. (1991) Handbook of Genetic Algorithms, Van Nostrand Reinhold, New York.

Goldberg, D.E. (1989) Genetic Algorithms in Search, Optimization and Machine Learning, Addison-Wesley, Reading, MA.

Helmy, M.W., Khalf, F. and Darwish, T.A. (1998) Well design using a computer model. SPE Drilling \& Completion Journal, March.

Holland, J. (1975) Adaptation in Natural and Artificial Systems. Ann Arbor, MI: University of Michigan Press.

Lewin, D.R. and Parag, A. (2003) A constrained genetic algorithm for decentralized control system structure selection and optimization. Automatica, 39, 10, October, 1801-1807.

McMillian, W.H. (1981) Planning the directional well - a calculation method. JPT, March, 952-962.

Miska, S. (1981) Theoretical description of a new method of optimal program design. SPEJ, August, 425-434.

Pongcharoen, P., Hicks, C., and Braiden, P.M. (2003) The development of genetic algorithms for the finite capacity scheduling of complex products, with multiple levels of product structure. European Journal of Operational Research, 152, 1, 1 January, 215-225.

Rabia, H. (1985) Oil Well Drilling Engineering: Principles and Practice, Graham \&Trotman, Oxford, UK. 
Rampersad, P., Hareland, G. and Pairintra, T. (1993) Drilling optimization of an oil or gas field. SPE 13694.

Reeves, C.R. (1997) Genetic algorthm for the operations research. Informs Journal on Computing, 9, 3, 231-250.

Sevaux, M and Dauzère-Pérès, S. (2003) Genetic algorithms to minimize the weighted number of late jobs on a single machine. European Journal of Operational Research, 151, 2, 1 December, 296-306.

Tate, D.M. and Smith A.E. (1995) A Genetic approach to the quatratic Assignment problem. Computers and Operations Research, 22, 73-83.
Taylar, H. and Mason, C.M. (1972) A systematic approach to well surveying calculations.SPEJ, December.

Vijande, J., Piñeiro, M.M., Mosteiro, L. and Legido, J.L. (2003) Estimation of carbonate-alcohol interaction parameters for Nitta-Chao group contribution model: application of a genetic Algorithm. Fluid Phase Equilibria, 212, 1-2, 15 September, 165-174.

Wilson, G.J. (1968) An Improved method of computing directional survey. JPT, August.

Final manuscript received in October 2003 